\title{
Semi-probabilistic method for residual lifetime of aluminothermic welded rails with foot cracks
}

\author{
S. Romano ${ }^{a}$, D. Manenti ${ }^{a}$, S. Beretta ${ }^{\mathrm{a}, *}$, U. Zerbst $^{\mathrm{b}}$ \\ a Politecnico di Milano, Department of Mechanical Engineering, Via La Masa 1, I-20156 Milan, Italy \\ ${ }^{\mathrm{b}}$ BAM Federal Institute for Materials Research and Testing, Division 9.1, D-12205, Germany
}

\section{A R T I C L E I N F O}

\section{Article history:}

Received 10 December 2015

Revised 16 May 2016

Accepted 19 May 2016

Available online $\mathrm{xxxx}$

\section{Keywords:}

Railway rails

Foot crack

Fatigue crack

Failure probability

Residual lifetime

\begin{abstract}
A B S T R A C T
One of the most frequent and dangerous failure modes in continuous welded rails is fatigue crack propagation terminated by brittle fracture. Due to the brittleness of the weld material and HAZ and the scatter in its mechanical properties, a statistical approach is necessary. The paper deals with surface cracks at the foot base of aluminothermic welded rails, developing a probabilistic methodology for determining the day by day prospective failure probability. The investigations presented here comprise weld material characterization, simulation of fatigue crack propagation and finally the determination of the failure probability using the Monte Carlo method. The effect of various parameters, such as axle weight, initial crack size, residual stresses, fatigue crack propagation threshold and date of inspection were analyzed. The results show that, independent of the date of the last inspection, almost any failure event happens in wintertime. This is in accordance with practical experience. However, from the proposed analysis it is evident that the main parameter controlling rail fracture is not only the minimum local temperature, but the temperature range over the whole year. Finally, the results are compared to the standard rail classification method.
\end{abstract}

(c) 2016 Elsevier Ltd. All rights reserved.

\section{Introduction}

One trend in the development of rail tracks is the increasing replacement of mechanically joined by continuously welded rails. Using technologies such as aluminothermic or flash-butt, the useful lifetime and in service reliability of the tracks are improved and problems of wear and dynamic overload are reduced. The consequences are better comfort for the passengers and a significant reduction of the costs of maintenance and management of railway [1]. Note, however, that these benefits are balanced by new risks because the welds become the main cause of rail failure. Some of the most frequent causes of failure are summarized in Fig. 1. During aluminothermic welding, additional heat is generated by the reduction of heavy metal oxides by aluminum. This characteristic feature makes the technique an advantageous method for welding railways rails in the field, particularly repair welds. However, there are not only advantages. The most severe detrimental effect is the possibility of fatigue crack nucleation, e.g., in the heat affected zone of the weld, which may lead to fatigue crack propagation and finally to rail fracture. As it is typical for welding, the residual

\footnotetext{
* Corresponding author.

E-mail address: stefano.beretta@polimi.it (S. Beretta).
}

stresses generated are tensile in most of the rail section and act as additional loading components.

An aluminothermic weld is schematically shown in Fig. 2. As can be seen, after welding, the weld is overhanging along the rail section except in the rail head region, where the excessive material is ground away. On the one hand this web stiffens the weld, on the other hand it generates additional (notch) stresses in some regions, particularly at the rail foot base, where the bending stress caused by the axle load of a passing vehicle is largest. The aim of the present work is a probabilistic analysis of the growth and fracture of a semi-elliptical surface crack originating in a weld at the foot base in the center line of an UIC 60 cross section rail. The crack site is also shown in Fig. 2. The results of the fracture mechanics analysis constitute the scientific background for specifying the demands on non-destructive testing and inspection intervals within the frame of a damage-tolerant design philosophy.

\subsection{Philosophy of the present analysis}

The philosophy of the present analysis follows the one elaborated in [2]. Starting from a crack of an initial size, defined by the detection limit of non-destructive inspection under in-service conditions, fatigue crack propagation is analyzed taking into account all loading components (Fig. 3). For surface cracks at the foot base, 


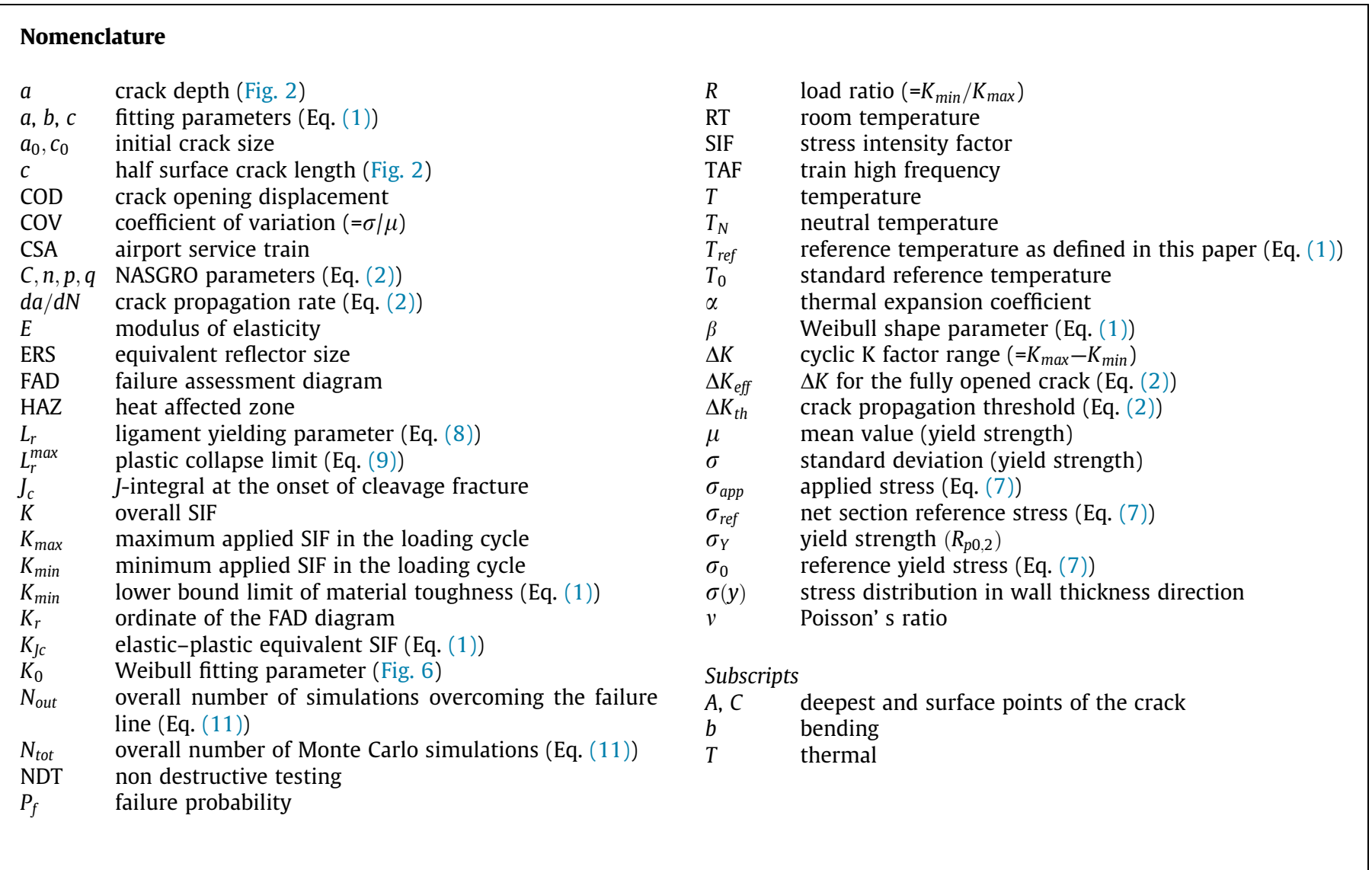

these are: (i) bending stresses from (dynamic) axle loads when a train passes by, (ii) thermal stresses that arise in continuously welded rail tracks due to hindered shrinkage (at low environmental temperatures) and extension (at high temperatures), and (iii) welding residual stresses, which replace the common residual stresses due to heat treatment and roller straightening from manufacturing. The additional notch stresses due to the stress concentration at the transitions from the overhanging weld to the rail ends is defined within the bending and thermal components and is determined through a finite element analysis (see Section 3). A more comprehensive discussion of the loading of rails is provided in [3].

Due to the seasonal differences in thermal stresses, cracks of the same size tend to grow slower in summer time than in the winter half year. A rail breaks when the maximum crack driving force, i.e., the maximum load in the loading cycle, reaches the fracture toughness of the material. The analysis starts with an inspection at a specific date. From that day on, both crack propagation and the maximum crack driving force are determined day by day and it is decided whether the rail would break or not. However, the analysis has to be statistically performed because some of the input parameters, most of all the material toughness, show significant scatter: as a consequence, the result is a failure probability. In this paper we consider, for a given traffic load, a probabilistic analysis and then we propose a simplified analysis for discussing the main variables in determining residual lifetime and the sensitivity to some calculation assumptions.

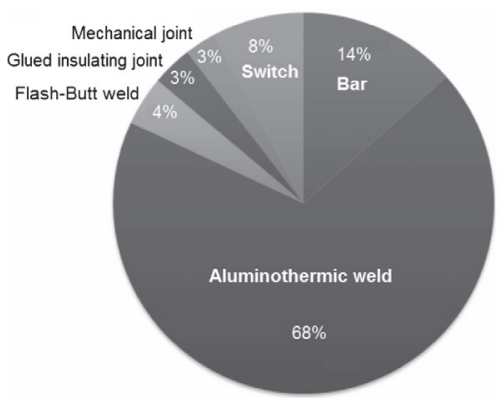

(a)

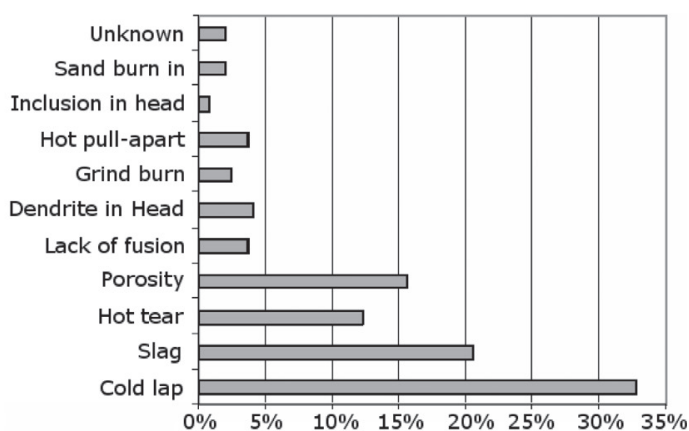

(b)

Fig. 1. Main causes of failure: (a) in railways, according to [41]; (b) in welded joints, according to [42]. 


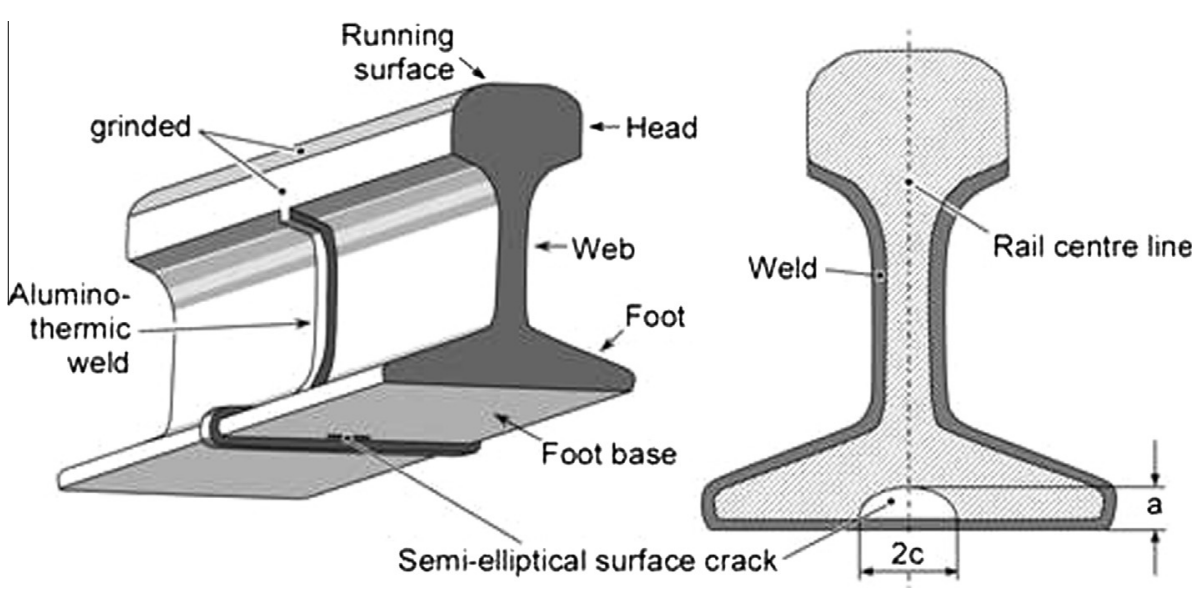

Fig. 2. Geometry of the welding and of the investigated crack.
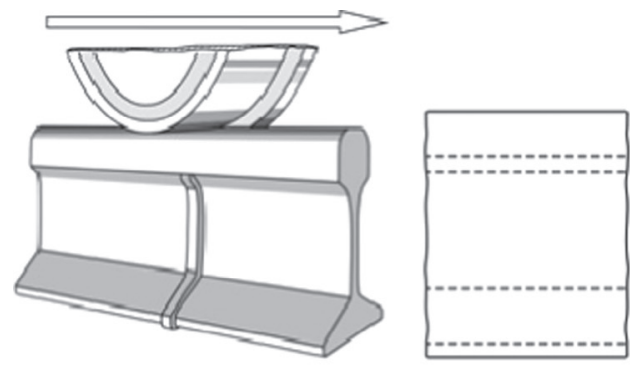

(a)

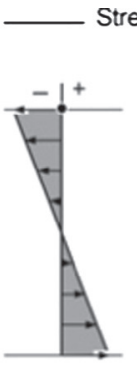

Axle load
Stress (axial direction)

$T<T_{N}$

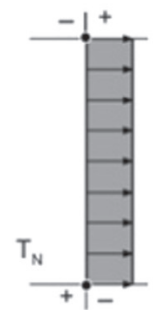

Thermal Stresses

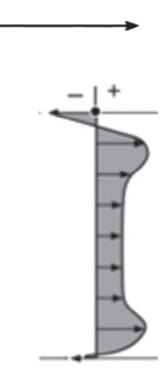

Residual Stresses

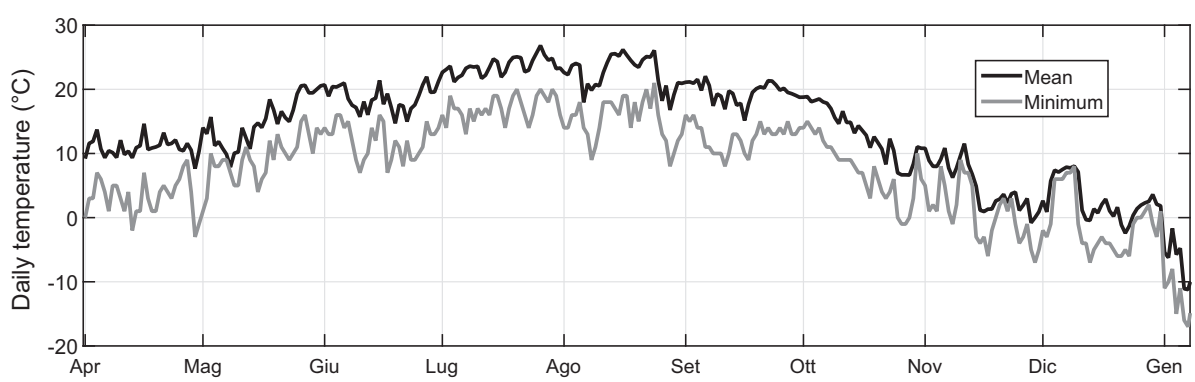

(b)

Fig. 3. Schematic of the rail: (a) different stress types acting on a welded joint $\left(T_{N}=\right.$ neutral temperature, see Section 2.2.2; (b) daily mean and minimum temperature during the year, influencing the thermal stress (temperatures measured in Saronno (IT)).

\section{Input data for assessment of rail welds}

\subsection{Material properties}

Dependent on the geographical site, a rail experiences year-round varying temperatures. For the present investigation, a location was chosen at which the average temperature two meters above ground varied between $-11^{\circ} \mathrm{C}$ and $26^{\circ} \mathrm{C}$ and the minimum temperature was a small as $-17^{\circ} \mathrm{C}$ in cold winter nights (see Fig. 3b). Accordingly, a series of mechanical characterization tests was carried out at different temperatures in the range between $-40{ }^{\circ} \mathrm{C}$ and $26^{\circ} \mathrm{C}$ (hereafter called room temperature).

\subsubsection{Specimens extraction}

A number of 8 tensile, $20 \mathrm{C}(\mathrm{T})$ and $6 \mathrm{SE}(\mathrm{B})$ specimens were extracted from two aluminothermic joints and they were subjected to mechanical tests [4] (see Fig. 4). Test pieces were located in the weld region, even if properties of the HAZ region could be slightly different [5].

\subsubsection{Yield strength}

The rail material investigated was wear resistant UIC 900A grade rail steel, with a required minimum ultimate tensile strength of $880 \mathrm{MPa}$. Mean yield strength of the weld material at room temperature and $-20^{\circ} \mathrm{C}$ were respectively $446.0 \mathrm{MPa}$ and $588.5 \mathrm{MPa}$ with a $\operatorname{COV}=0.02$, a value slightly lower than the indications by Wallin [6].

\subsubsection{Fracture toughness}

Fracture toughness was thoroughly investigated by a series of fracture tests at RT, $T=-20^{\circ} \mathrm{C}$ and $T=-40^{\circ} \mathrm{C}$ according to ASTM E1820 standard [7]. Even if some specimens manifested several pop-in events, the toughness $J_{c}$ was calculated at the first pop-in occurred during each test. 
The temperature dependency and the scatter of ferritic steels of a certain range of yield strength are usually described by the Master Curve approach according to ASTM E1921 [8]. Note, however, that the rail weld material at test temperature is in the lower shelf of the Master Curve, rather than to the ductile-to-brittle transition range. Because of this fact, the authors determined an empirical correlation, which, although based on the basic equation of the Master Curve, was individually fitted to the data using the Maximum Likelihood method [9]. In details, fracture toughness was described with [6]:

$K_{J c}(T)=K_{\min }+\left\{a+b \cdot \exp \left[c \cdot\left(T-T_{r e f}\right)\right]\right\} \cdot\left[\ln \left(\frac{1}{1-P_{f}}\right)\right]^{1 / \beta}$

with the fit parameters being $a, b, c$, transition temperature $T_{\text {ref }}$ and $\beta$. $K_{J c}$ denotes the toughness in terms of $K$, but formally derived from the critical $J$-integral $J_{c}$ by the relation $K_{J c}=\sqrt{\frac{J_{c} \cdot E}{\left(1-v^{2}\right)}}$.

It is worth mentioning that the minimum toughness was set to $K_{\min }=16 \mathrm{MPa} \sqrt{\mathrm{m}}$ on the base of the empirical data (see Fig. 5) and that the mean toughness at room temperature is approximately $37.5 \mathrm{MPa} \sqrt{\mathrm{m}}$ with $\mathrm{COV}=0.35$. Data fit for two temperatures is shown in Fig. 5, where data are not shown explicitly for confidentiality about test results.

The temperature dependency of the toughness including its scatter is shown in Fig. 6 together with literature data [10-13]. Again, it is of purely empirical nature and valid only for the temperature range investigated, but it is clearly visible that below $T=-10^{\circ} \mathrm{C}$ toughness of rail aluminothermic welds is in the lower shelf region.

\subsubsection{Fatigue crack propagation rate/fatigue crack propagation threshold}

The fatigue crack propagation rate versus the cyclic crack driving force $\Delta K$ was obtained for stress ratios $R=K_{\min } / K_{\max }$ of 0.2 and 0.7 for room temperature, $-20^{\circ} \mathrm{C}$ and $-40{ }^{\circ} \mathrm{C}$ (Fig. 7). Note that no significant temperature dependency could be identified. What is, however, noticeable is the increasing fan-out of the curve when it comes to higher crack tip loading $\Delta K$. The possible reason is a mixture of failure mechanisms in that the fatigue crack propagation is interrupted by static fracture mechanisms, i.e., cleavage. Crack growth data were described with the NASGRO equation:

$\frac{d a}{d N}=C \cdot \Delta K_{e f f}^{n} \cdot \frac{\left(1-\Delta K_{t h} / \Delta K\right)^{p}}{\left(1-K_{\max } / K_{J c}\right)^{q}}$

where

$\Delta K_{e f f}=\Delta K \cdot\left(\frac{1-f}{1-R}\right)$

with $f=K_{o p} / K_{\max }$ being the Newman's closure function [14]. Coefficients $C$ and $q$ are empirically fitted to the data sets, taking $K_{J c}$ as the maximum SIF applied during each test, while $n$ is assumed to be 3 , as expected in the Paris range of the $d a / d N-\Delta K$ curve for steels [15].

No threshold data were available for fatigue crack propagation rates below $d a / d N=10^{-7} \mathrm{~mm} /$ cycle, used for specifying the threshold $\Delta K_{\text {th }}$ according to ASTM E647 [16]. Therefore, the final rail life assessment did not take into account any fatigue crack propagation threshold, but simply extrapolated the $d a / d N-\Delta K$ data of the Paris range to lower $\Delta K$. Such an assumption could appear very crude but in presence of humid environment, as it might occur for rails, small cracks can propagate at very low $\Delta K$ values [17]. However, in order to check whether there would potentially be an effect of $\Delta K_{t h}$, reference values for the subsequent analysis were fixed equal to the lower limit values suggested by BS7910 [15] for welded steels, which are conservative respect to literature results [13]. Fig. 7 illustrates the quality of the NASGRO equation for the fitted parameters, showing the link between propagation instabilities and fracture toughness variability when $K_{\max }$ approaches $K_{J c}$.

Note that, despite the $C$ coefficient of the NASGRO equation is considered as a constant, the intrinsic variability of the fracture toughness (see Section 2.1.3) involves a variable crack propagation rate too, as discussed in Section 4.

\subsection{Loading data}

\subsubsection{Load spectra from vehicle crossing}

Two classified loading spectra for a rather heavy (TAF) and a rather lightweight (CSA) train are considered, as shown in Fig. 8. The full-capacity load of TAF (which is composed by 8 elements) is $1812 \mathrm{~kg}$, while the 4 elements CSA has an overall full-capacity mass of $506 \mathrm{~kg}$. These spectra were obtained through static FE simulations using Abaqus 6.13, assuming the weld to be positioned in the middle of two sleepers, which is the most stressed point. The distance between two sleepers in the track is $l=600 \mathrm{~mm}$. The flexibility of the sleeper-ballast system was modelled as a series of two spring elements [18], having an overall stiffness of $58.76 \mathrm{MNm}^{-1}$, in line with the measurements reported by Berggren [19]. The spectrum of every train was finally extracted from its quasi-static stress history in the time domain, using the Rain Flow method. Of course, it is not only the dead weight, which controls the axle load the rail is subjected to: the passing vehicles as well as the track basement form a dynamic system such that the loading of successive axles will be quite different even though their dead weights are identical, so these spectra are just a simplification of the real bending stresses acting on the rail. Moreover, both the weight of the train and the stiffness of the subgrade have an intrinsic variability, dependent on several factors, which are not the subject of the present analysis. In order to make safe previsions, the bending load of the train considered (shown in Fig. 8c) is determined as a conservative value for fully loaded vehicles.

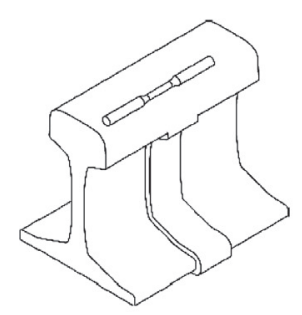

(a)

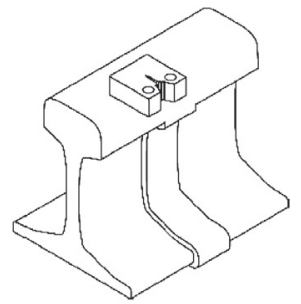

(b)

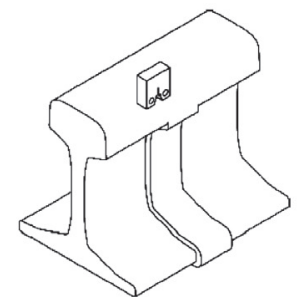

(c)

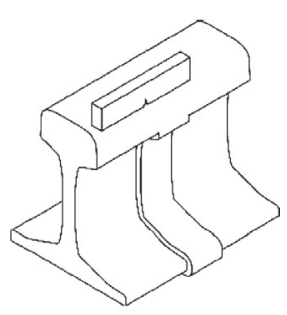

(d)

Fig. 4. Example of specimens extraction. (a) Tensile; (b) C(T) horizontal plane; (c) C(T) vertical plane; (d) SE(B). 


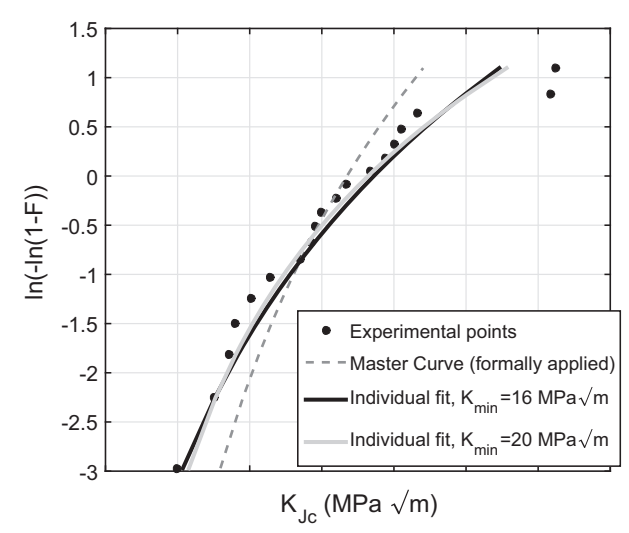

(a)

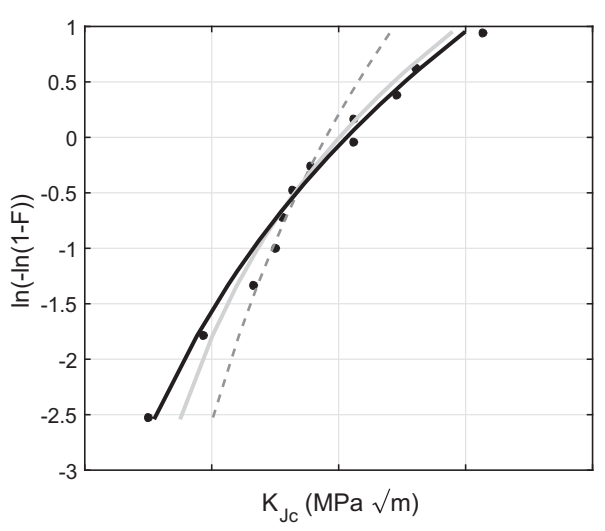

(b)

Fig. 5. Comparison between Master Curve approach and experimental fit on data for (a) $T=25^{\circ} \mathrm{C}$; (b) $T=-20{ }^{\circ} \mathrm{C}$.

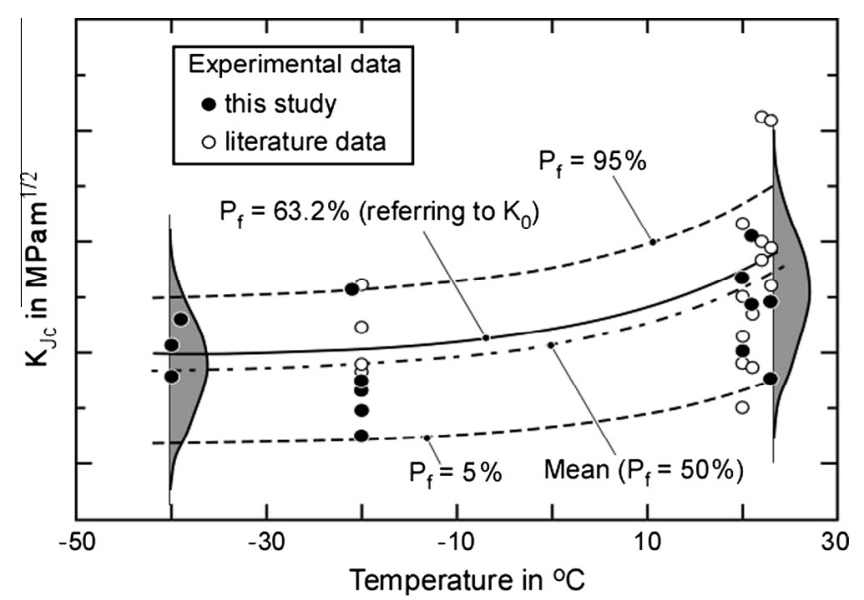

Fig. 6. Empirically fitted Master Curve-type expression. Literature data according to [10-13].

Even if the spectra are just a simplification of the real bending stress acting on the rail, they can surely be used to discuss the model and to compare the results proposed.

\subsubsection{Thermal stresses}

As mentioned in Section 1.1, thermal stresses are the consequence of prevented extension or shrinking in continuously welded tracks. What matters is not the absolute temperature, but the difference between the actual service temperature and the so-called neutral temperature $T_{N}$, which designates the temperature at which the axial force in the rail is zero. Self-evidently this is the case at the moment when the track is installed. The thermal stresses can easily be determined by

$\sigma_{T}=\alpha \cdot E \cdot\left(T_{N}-T\right)$

with $\alpha$ being the coefficient of thermal expansion and $E$ being the modulus of elasticity. According to the Italian railway standard [20], the neutral temperature in Lombardy should be $T_{N}=30^{\circ} \mathrm{C} \pm 3{ }^{\circ} \mathrm{C}$. Following the same path presented for the bending stress, the thermal load is calculated as a safe upper bound, fixing the neutral temperature to the maximum admissible by the standard: $T_{N}=33^{\circ} \mathrm{C}$. Note, however, that the simple logic of $T_{N}$ being the temperature at track installation is challenged in practice, since there might be a number of influencing factors on $T_{N}$, e.g., roadbed freeze-thaw cycles, cumulative vehicle braking on limited track sections, rail repairs and others (cf. [3]).

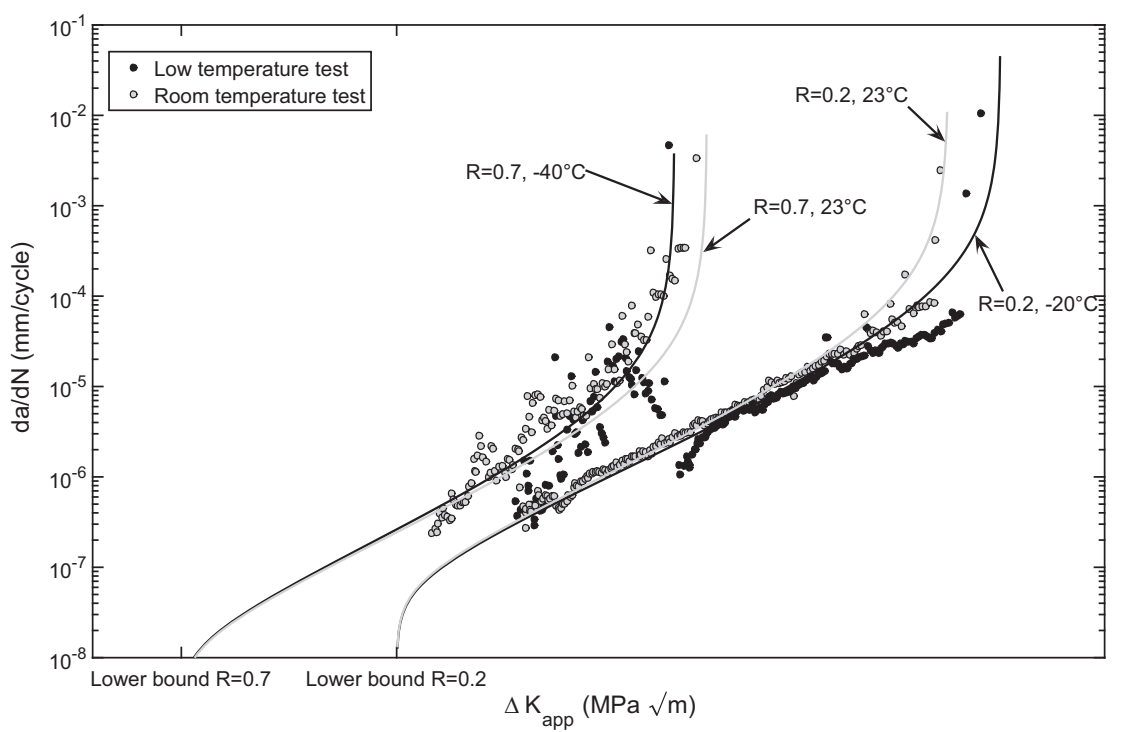

Fig. 7. Propagation tests for $\mathrm{SE}(\mathrm{B})$ specimens and NASGRO fit for $R=0.7$ (lower bound estimates for crack propagation threshold according to BS 7910). 


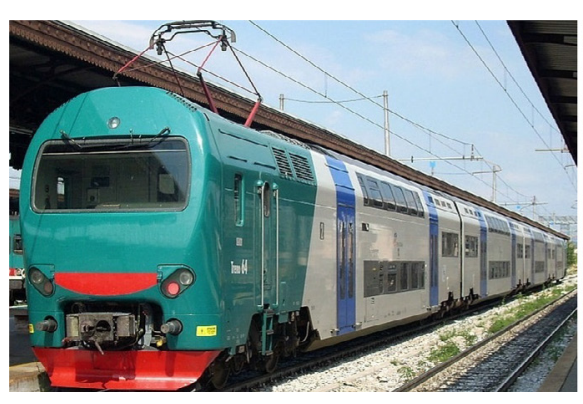

(a)

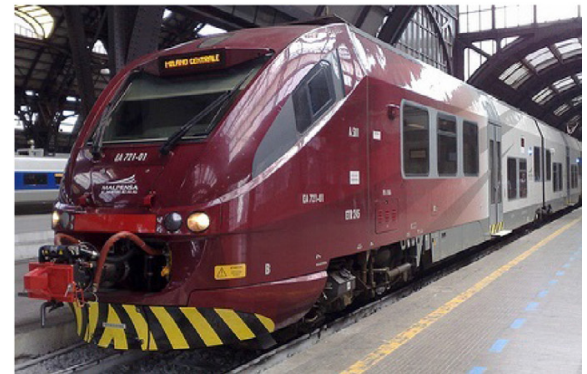

(b)

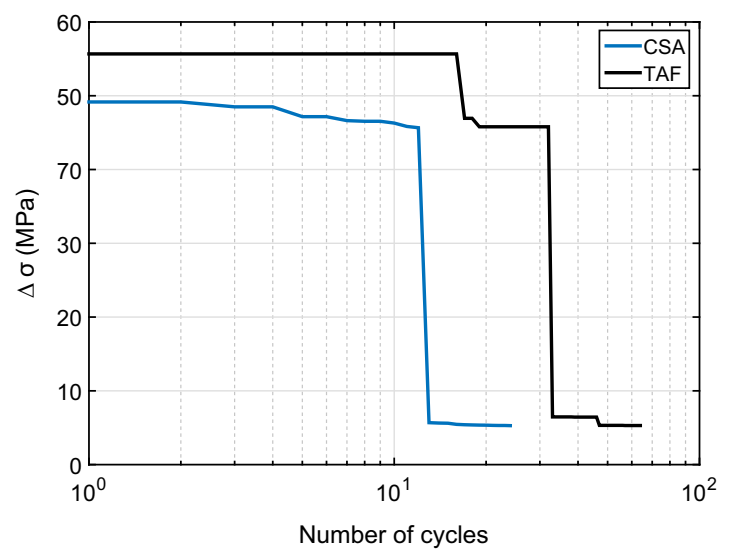

(c)

Fig. 8. Train considered in the analysis: (a) TAF; (b) CSA; (c) quasi-static bending spectra.

\subsubsection{Welding residual stresses}

As mentioned above, in butt-welded rails the welding residual stresses replace the residual stresses from roller straightening and heat treatment.

An axial welding residual stress profile along the rail center line of a flash butt weld is shown in [21]. This was obtained by measurements and finite element analysis and characterized by tensile stresses in the web and parts of the head and foot of the rail section and by compressive stresses below the running surface. At the foot base, both the simulations and two measurement points were close to zero or have even slight compressive stresses. Note, how-

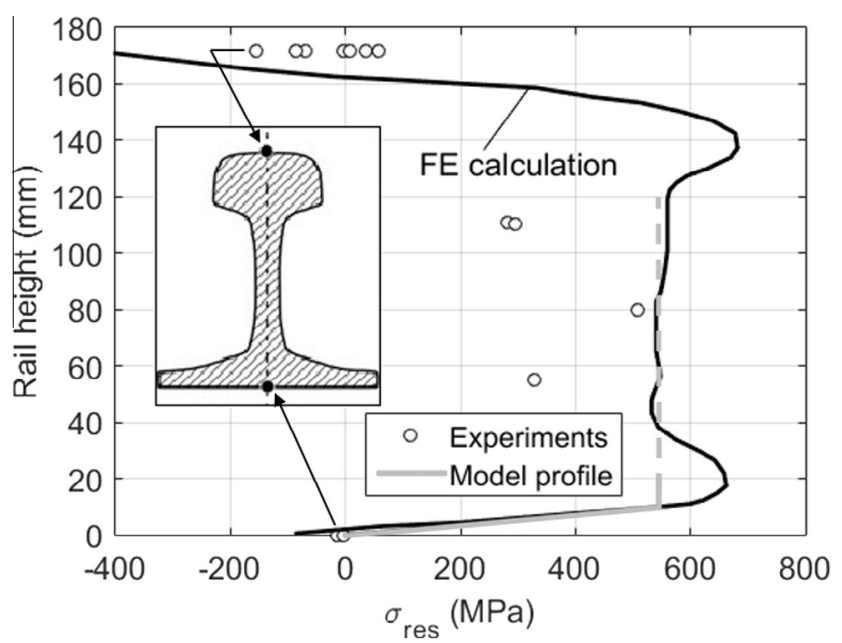

Fig. 9. Axial welding residual stress profile across the weld center line of a flash butt weld [21] and this model assumption, together with experimental results. ever, that any determination is difficult due to the steep stress gradient in these parts. In the present work, this stress was approximated by a straight line going from $0 \mathrm{MPa}$ on the foot surface to the yield stress at a depth of $10 \mathrm{~mm}$, as depicted in Fig. 9. One could argue that a residual stress profile obtained for a flash welded rail cannot be simply transferred to an aluminothermic weld. That this, nevertheless, was done in the present analysis is simply due to the lack of relevant information. However, the authors do not expect huge differences (see Section 6) and the data are certainly sufficient for developing and demonstrating the procedure for fracture mechanics assessment, which is the goal of this paper.

\section{Fatigue and fracture assessment}

\subsection{Stress intensity factor}

The $K$ factor has to be determined separately for the deepest and the surface points of the crack, which in the following will be designated by $A$ (deepest point) and $C$ (surface points). Accordingly, the corresponding $K$ factors will be designated by $K_{A}$ and $K_{C}$. It is common practice to determine individually stress intensity factors for all loading components and subsequently to superimpose these. To that purpose, it is first necessary to classify the loading with respect to what is designated as primary and secondary stresses in a fracture mechanics analysis. Primary stresses are caused by external loading, such as forces and moments, while secondary stresses are the result of suppressed deformation. The latter is usually the case for residual and sometimes for thermal stresses. However, what matters in a fracture mechanics analysis is whether the stresses are self-equilibrating within the section that carries the crack. Even though residual stresses self-equilibrate across the volume of the overall component, this might not be the case 


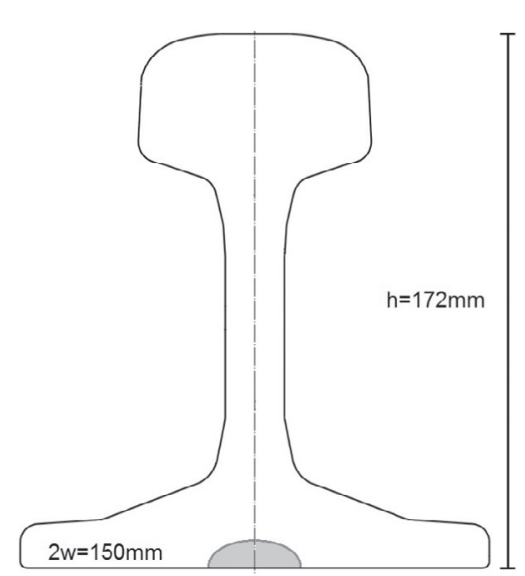

(a)

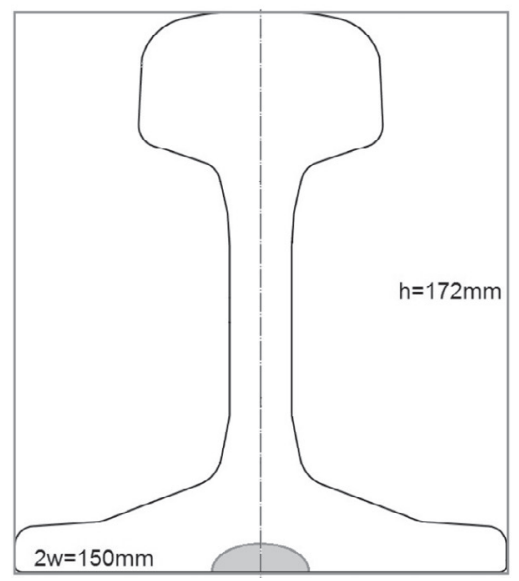

(c)

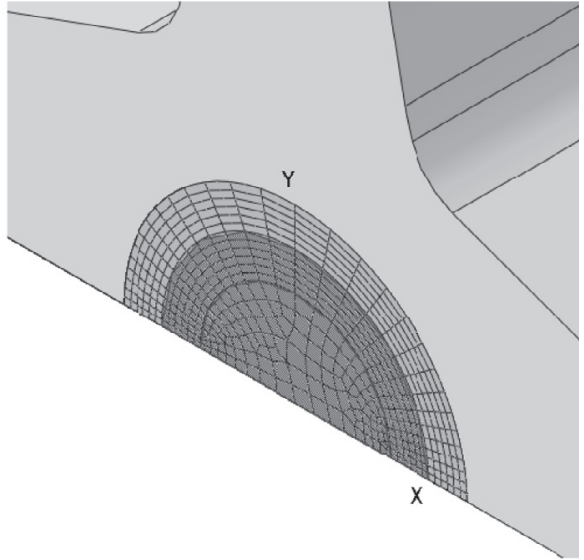

(b)

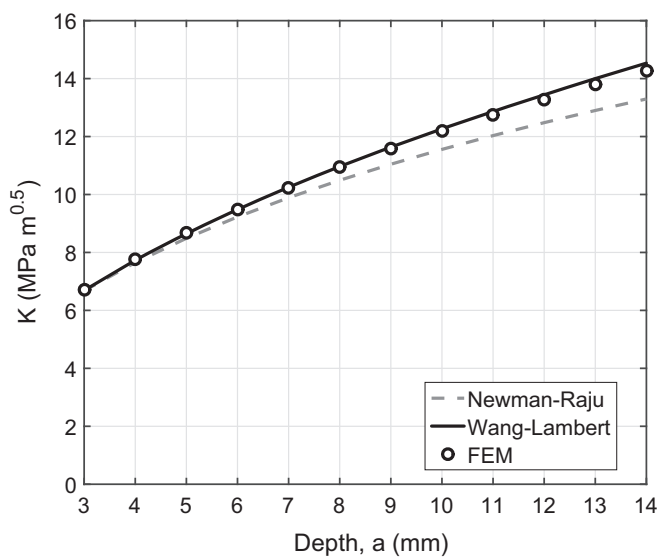

(d)

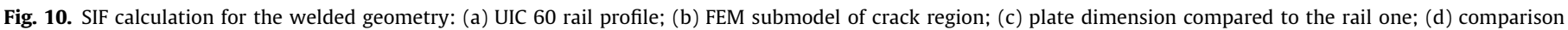
between different SIF calculation methods.

with respect to the relevant section, like in the present study. For this reason, all the stress components in play can be classified as primary, simplifying the analysis since the overall SIF, $K$, can be obtained by simple superposition:

$$
K=K_{\text {axle load }}+K_{\text {thermal stress }}+K_{\text {residual stress }}
$$

The question is now how to calculate the crack tip stress intensity factor. Different approaches were tried in [4]: one possibility is to rely on numerical FE calculations for the particular geometry under investigation (Fig. 10b), while a simpler choice can be the use of analytical and general weight functions based on bending and tension on an infinite plate, such as Newmann and Raju [22] and Wang and Lambert [23] solutions. A systematic comparison between FE analyses and WF solutions was made by a series of simulations with ABAQUS 6.10 and calculating SIF from the $J$ integral [24]: cracked rails were meshed with C3D20 quadratic elements with a typical radial dimension of $200-400 \mu \mathrm{m}$ after a convergence check. The FE analyses showed a good comparison with FE solutions by adopting the substitute geometry of a rectangular plate setting the plate thickness equal to the rail height, which for a UIC 60 profile is $h=172 \mathrm{~mm}$, as shown in Fig. 10 [4]. In particular, the model chosen was Wang-Lambert (Eq. (6)), which is able to take into account the stress decrease far from the notch, and predicts results very close to FE ones for crack depths up to $15 \mathrm{~mm}$, which are above the maximum values considered in the present analysis.
A series of FE analyses were then carried out on a 3D model of the welded rail, built considering a joint subjected to a bending load $P$ and supported by six sleepers (see Fig. 11a). The welded joint has been modelled with a very fine mesh with quadratic C3D20 elements of $100 \mu \mathrm{m}$, considering a $6 \mathrm{~mm}$ overhang from the base rail material with a fillet radius of $0.5 \mathrm{~mm}$ (see Fig. $11 \mathrm{~b}$, c). These dimensions are in agreement with the assumption in [25] and they can be seen as a lower bound for in-field welds. The SIF for a centered crack at the base of the weld was then been calculated as:

$K=\int_{0}^{a} \sigma(y) \cdot m(y, a) \cdot d y$

In Eq. (6), $m(y, a)$ is the weight function [26] for the direction considered (depth or surface), while $\sigma(y)$ is the stress distribution on the crack face, determined by FE analysis. The solutions from WF were compared with a second series of FE analyses with a cracked submodel introduced at the base of the weld [4] (mesh size in the submodel of approx. $100 \mu \mathrm{m})$ : the comparison between WF and FE solutions showed a maximum error of $20 \%$ for cracks with $a>2 \mathrm{~mm}$ and $0.4<a / c<1$. For the sake of the present calculations, we adopted the WF solutions, even if their precision was not checked, for describing crack growth for smaller cracks.

Note that the weight function of Eq. (6) by its nature is a 2D solution, e.g. it does not take into account any stress variation along the rail foot. In the case of axle loads and thermal stresses, 


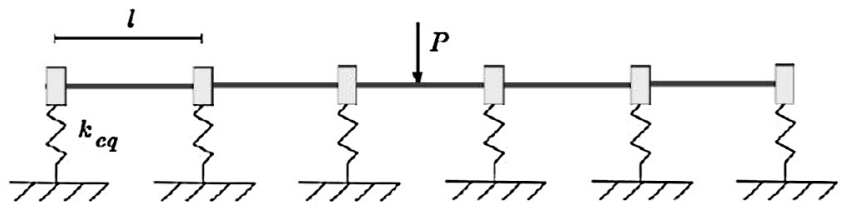

(a)

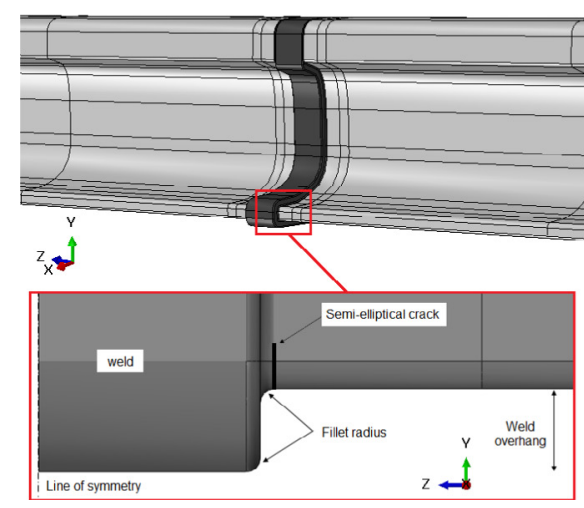

(b)

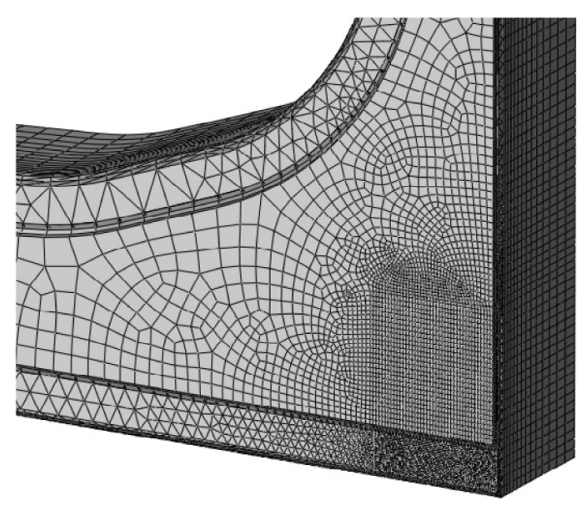

(c)

Fig. 11. Finite element model of the welding: (a) model of rail and load; (b) 3D model of weld geometry; (c) dense mesh in the crack region.

a series of FE analyses with cracks located in different positions at the rail foot has shown that crack propagation obtained by assuming a centered crack is a good approximation [4]. As for residual stresses, considering the high uncertainty in specifying the exact values of these stresses, it is conservative to assume zero residual stresses along the whole foot base of the rail. It is then reasonable to apply Eq. (6) to both the surface and deepest points of the crack.

\subsection{Initial crack size}

Since the model is intended to give life estimations for cracked joints, the minimum flaw size should be determined according to the limit of actual non destructive testing, so that the simulation comprises all the detectable crack life. For railways, in particular, the most common technique is ultrasonic testing. It is very difficult to determine the minimum detectable crack, since it depends from several factors, but a lower bound estimation is made considering a crack having the same ERS of a flat bottom hole of $2 \mathrm{~mm}$ diameter, which is used to calibrate ultrasounds probes for railways [27]. The stabilization of the crack shape ratio for an aluminothermic joint has been studied numerically in based on real failures: it was seen that, for different initial defect sizes, $a / c$ rapidly converges to a value of almost 0.4 in the early crack propagation time. This is the reason why, in the analyses, the initial crack shape is set to this stabilized aspect ratio, which corresponds to an initial flow depth $a_{0}=0.9 \mathrm{~mm}$. This value can be considered a lower bound size for NDT inspection, however, it should be noted that most of crack propagation time happens below that limit. This is the reason why the model will not determine the real life of welded joints, but the expected time to failure for a cracked one in order to determine its inspection interval [28].

\subsection{Crack driving force and crack propagation}

While the dynamic axle load, which is changing during the day according to the bending spectrum of the particular sequence of trains passing on the weld, is of cyclic nature, thermal stresses are considered to be time independent for the calendar day under investigation and residual stresses do not change during the life of the weld. Consequently, their treatment in the fatigue crack propagation and fracture analysis is different. In the fatigue crack propagation, the axle load and its magnification due to the weld transition notch contribute to $\Delta K$, whereas the (monotonic) residual and thermal stresses only contribute to the stress ratio $R=K_{\min } / K_{\max }$ (and so to the crack propagation curve through the Newman's closure function) in that they add the same additional value to $K_{\min }$ and to $K_{\max }$ induced by the train wheels.

Given a welded joint with a certain crack size and prospective toughness $K_{J c, i}$, its growth rate is fully determined (we have shown in Section 2.1.4 its dependency on the fracture toughness) and the day-by-day fatigue crack propagation can be simulated. The fracture mechanics analysis, at each step, has to be performed separately for the deepest and the surface points, $A$ and $C$, of the crack, meaning that the crack aspect ratio $a / c$ is explicitly determined during the analysis.

For assessing crack propagation, the $R$ ratio of each loading cycle is determined by superimposing the $\Delta K$ from dynamic axle loading to the $K$ values from the thermal and residual stresses. The thermal stress considered for the definition of the crack propagation curve is calculated according to the average temperature of the day, since fatigue crack propagation is a cumulative process [2]. Superimposing all loading components in terms of $K$, the $R$ ratio for the deepest point of the surface crack was seen to range between 0.4 and 0.8 during the whole fatigue life propagation, while for the surface point the range is 0.5-0.7.

On the contrary, as for the final fracture, the maximum SIF is determined considering the minimum daily temperature, which usually occurred over night: fracture is then predicted for the crack point which reaches the failure criterion earlier, as discussed in the following section.

An example of crack propagation supposed to start in April, from a semi-elliptical crack having the minimum depth detectable by UT ( $a_{0}=0.9 \mathrm{~mm}$ and shape ratio $a_{0} / c_{0}=0.4$, see Section 3.2$)$ is shown in Fig. 12, where three fatigue crack propagations related to different percentiles of the fracture toughness are shown. It can be seen that a lower $K_{J c}$ involves a faster fatigue crack propagation and how large the scatter in the fatigue life between different welds can be. 


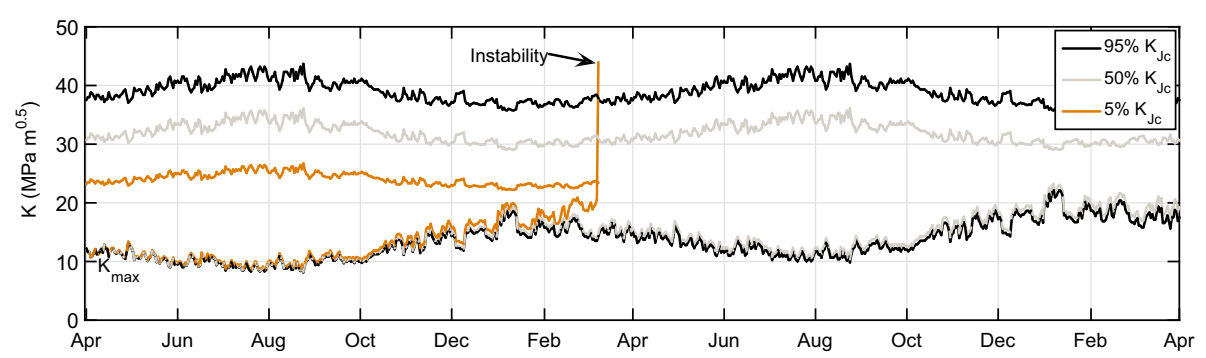

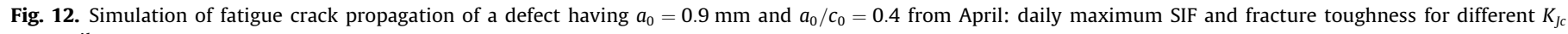
percentiles.

\subsection{Prospective failure into $F A D$}

The final point to be analyzed is the failure criterion: the brittle fracture is usually defined as the moment in which the applied SIF overcomes the fracture toughness of the weld, without taking into account any ligament plasticity effect: $K_{\max }>K_{J c}$. In fact, because of the low toughness of the rail steel highlighted in Section 2.1.3, one could suspect that the rail should fracture under small-scale yielding conditions, which means that the complete fracture mechanics analysis could be based on the linear elastic $K$ concept, but this has not necessarily to be the case. In the more general application, $K$ has to be replaced by a parameter such as the $J$ integral or it has to be corrected for ligament yielding by an $f\left(L_{r}\right)$ function of assessment procedures such as R6 [29], BS7910 [15] or SINTAP/FITNET [30].

In the present analysis, the crack driving force is determined for elastic-plastic ligament deformation and is based on a Failure Assessment Diagram (FAD) approach. Normalizing $K$ by the toughness of the material, $K_{J c}$, the parameter $K_{r}$ is obtained which refers to the ligament yielding parameter $K_{r}$ by $f\left(L_{r}\right)$.

$K_{r}=\frac{K}{K_{J c}}=f\left(L_{r}\right)=f\left(\frac{\sigma_{r e f}}{\sigma_{Y}}\right)$

In Eq. (7), $\sigma_{\text {ref }}$ is a net section reference stress of the component with crack, which is usually taken from a compendium, and $\sigma_{Y}$ is the yield strength of the material. In the present study, $f\left(L_{r}\right)$ is determined by Eq. (8) [30]:

$f\left(L_{r}\right)=\left(1+0.5 \cdot L_{r}^{2}\right)^{-1 / 2} \cdot\left(0.3+0.7 \cdot \exp \left(-\mu \cdot L_{r}^{6}\right)\right)$

with $\mu=\min \left\{\begin{array}{l}0.001 \cdot E / \sigma_{Y} \\ 0.6\end{array}\right.$

Eq. (8) is valid for materials which are not expected to display a yield plateau in the range $0 \leqslant L_{r} \leqslant L_{r}^{\max }$, with

$L_{r}^{\max }=0.5 \cdot\left[\left(\sigma_{Y}+R_{m}\right) / \sigma_{Y}\right]$

being the plastic collapse limit. In order to improve the accuracy of such an analysis, we have here adopted the suggestions in [31], where $\sigma_{Y}$ is replaced by a reference yield stress $\sigma_{0}$. Note that adopting the reference yield stress requires a modification of Eq. (7) to Eq. (10):

$K_{r}=\frac{K}{K_{J c}}=f\left(L_{r}\right)=f\left(\frac{\sigma_{a p p}}{\sigma_{0}}\right)$

where $\sigma_{\text {app }}$ is the applied stress on the component without crack. $\sigma_{0}$ was calculated by the solutions in [32] for a rectangular plate containing a semi-elliptical surface crack as substitute geometry. As in the case of the $K$ factor, the solutions for $\sigma_{0}$ distinguish between the deepest and the surface points of the crack and are able to consider combined tension/bending loads.

Whether a component will break or not is decided by the comparison of the location of an assessment point $\left(K_{r}, L_{r}\right)$ with respect to the $K_{r}-L_{r}$ failure line: as long as its position is inside the space circumscribed by the FAD line, the component is regarded as safe. When it crosses this line and falls outside, it is potentially unsafe $\left(K_{r}>f\left(L_{r}\right)\right)$. In the present case, things are rather easy: since the toughness of the material, $K_{J c}$, is considered to be crack size independent (no $R$ curve approach), the assessment point is only affected by $K$ and $\sigma_{\text {ref }}$ and by the yield strength of the material. Moreover, both the thermal and residual stresses can be considered as primary stresses (see Section 3.1), reason why no interaction factors between primary and secondary stresses has to be determined and all loading components are assumed to contribute to $L_{r}$. In contrast to the assessment point, the FAD line is only material dependent.

An other point to be discussed is whether an elastic-plastic analysis using the FAD approach is necessary or whether a linear elastic analysis exclusively based on the $K$ factor concept would have been sufficient. Fig. 13 provides a different view of what shown in Fig. 12, considering the development of the assessment path (the curve formed by shifting the assessment point towards the failure line with increasing load or crack size) in the FAD for points $A$ and $C$ of the crack, considering 50 daily TAF trains. The influence of the fracture toughness percentile is shown in Fig. 13a fixing the environment temperature to $T=-10^{\circ} \mathrm{C}$, while the variation associated to a temperature of $T=10^{\circ} \mathrm{C}$ is depicted in $13 \mathrm{~b}$, fixing a $K_{J c}$ percentile of 0.5 . The smaller $K_{r}$ at the crossing point between the assessment path and the FAD line, the larger the effect of elastic-plastic ligament yielding on the stress intensity factor. It shows up that there is indeed some effect for both points of the crack, and in particular for the deepest one when the dimension increases. Moreover, an important parameter as the irregularity between the wheel and the rail, that in this assessment is not considered, can considerably increase the bending stress and, as a result, the $L_{r}$ value [32]).

\section{Day-per day determination of the failure probability}

The general philosophy of this analysis has already been described in Section 1.1. Based on the minimum temperature of each day (which corresponds with a maximum thermal loading) it has to be established whether the rail would break or not. However, such a statement is not possible on deterministic grounds because of the scatter in the input parameters: (i) loads on the rails; (ii) material parameters.

As for the loads induced by the train traffic, our aim is here to provide (as it will be seen in 4.2) a simplified tool able to calculate the residual lifetime of a welded joint under a given loading scenario and therefore the variability of the bending loads has been ignored and we have considered the engineering upper limit of train loads. The rationale behind this assumption, apparently too simple, is that the variability of the train loads has a negligible effect on the variability of rail bending loads, since they are but rather controlled by the local soil-infrastructure interaction and 


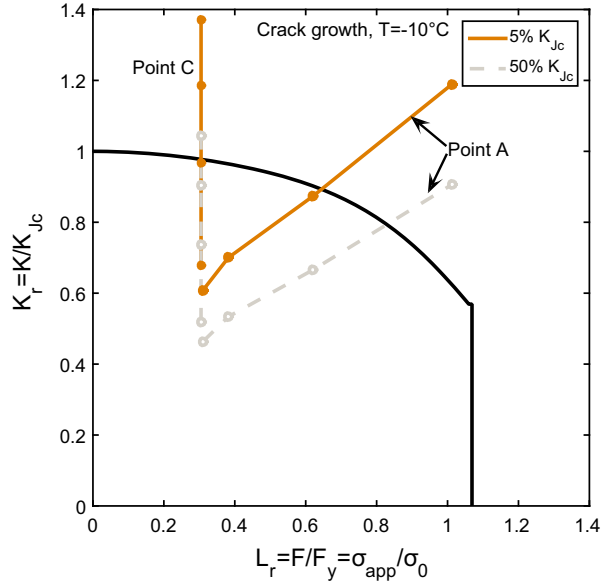

(a)

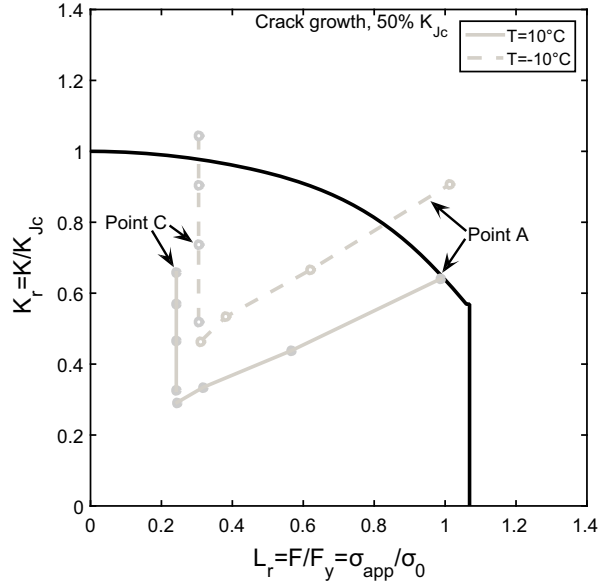

(b)

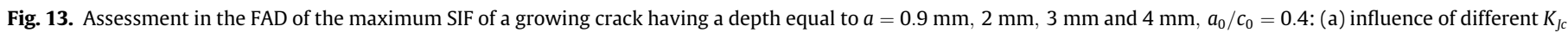
percentiles; (b) influence of environment temperature.

by the rail irregularity $[33,34]$. These two effects could be easily incorporated in the present semi-probabilistic analysis.

Considering material parameters, apparently there are different statistical variables in the fracture assessment: (i) the fracture toughness; (ii) the yield strength; (iii) the crack growth parameters ( $C, n$ and $\Delta K_{t h}$ in Eq. (2)). We only considered the first two variables because of the following reasons:

- $\Delta K_{\text {th }}$ has not been included in the analysis and, as it will be discussed in Section 6, it has a minor effect on residual lifetime of a welded rail;

- the $C$ and $n$ parameters have such a strong correlation [35] that usually only the variability of $C$ is taken into account. However, propagation of defects in welded rails occurs in the region of the $d a / d N$ curve where $K_{J C}$ causes a variation of the crack growth rate (experienced in the crack propagation tests) that largely exceeds the typical variability of the growth rate in the Paris region [36].

\subsection{Monte Carlo analysis}

Two random variables have been considered in the probabilistic analysis: (i) the fracture toughness of the welded material described by Eq. (1); (ii) the yield strength of the welded material that has been modelled as linearly dependent on temperature [30] with a $C O V=0.03$ [6].

The Monte Carlo analysis were performed extracting $10^{5}$ percentiles pairs from the two distributions, using the Latin Hypercubes sampling in order to increase the precision, and calculating crack propagation under a service load of 50 TAF trains per day, under the daily temperatures of Fig. 3b. The day-by-day crack propagation was calculated for the $10^{5}$ prospectively different welds (see Fig. 14a). The failure probability, for each day, was then calculated as:

$P_{f}=N_{\text {out }} / N_{\text {tot }}$

where $N_{\text {out }}$ is the number of analysis that yielded assessment points at or above the FAD line and $N_{\text {tot }}=10^{5}$ is the total number of trials.

According to [37], the percentage error associated to a 95\% confidence band for the so calculated failure probability is:

$\epsilon \%=2 \sqrt{\frac{1-P_{f}}{N_{t o t} \cdot P_{f}}}$
Fig. 14b shows the results of the crack growth calculations (only for the surface point C) for the day 279 in the FAD diagram, while day per day cumulative failure probability for the rail is shown in Fig. 15. It is worth remarking that if $K_{r}=1$ (absence of plasticity correction) the failure probability would be underestimated approximately by $50 \%$ for the entire time history. The full Monte Carlo simulation, although correct from a theoretical point of view, has needed a very huge amount of memory and computational time.

\subsection{Simplified probabilistic approach}

In order to avoid the computational burden, we considered a second simplified method that did not calculate crack propagation for different $K_{J c}$ values, but fracture toughness was fixed to a percentile: $P_{K_{J c}}=1 \%$. At the end of every day, crack length being deterministic, a Monte Carlo analysis $\left(N_{\text {tot }}=10^{6}\right)$ on $K_{J c}$ and $\sigma_{y}$ introduced the material properties variability, creating a cloud in the FAD. A comparison between the two methods is shown in Fig. 15, where it can be seen that the two methods converge when $P_{f}=1 \%$.

\section{Applications of the simplified probabilistic analysis}

In the following, the simplified probabilistic analysis was used for the investigation of a number of parameters on the fatigue growth and fracture of semi-elliptical surface cracks at the weld foot base. The reference case here considered was again the propagation considering $50 \mathrm{TAF}$ trains per day, under temperatures measured in Saronno and an initial crack size with $a_{0}=0.9 \mathrm{~mm}$ $\left(a_{0} / c_{0}=0.4\right)$. Last inspection is assumed to have taken place on April 1st. The results are shown in Fig. 16: they illustrate that the failure probability increases with crack length, but failure is generally expected in wintertime. It is also interesting to observe the simplified calculations (propagation calculated with $1 \%$ percentile for $K_{I c}$ ) in terms of the prospective $K_{\max }$ at the end of each day compared to the $1 \%$ percentile for $K_{J c}$ : when the two curves get in touch (day 279), then $P_{f}$ calculated with the simplified option is above $1 \%$.

\subsection{Effect of the date of last inspection}

The same flaw as in Fig. 16 was studied considering its propagation starting from three different periods, equally spaced in the 


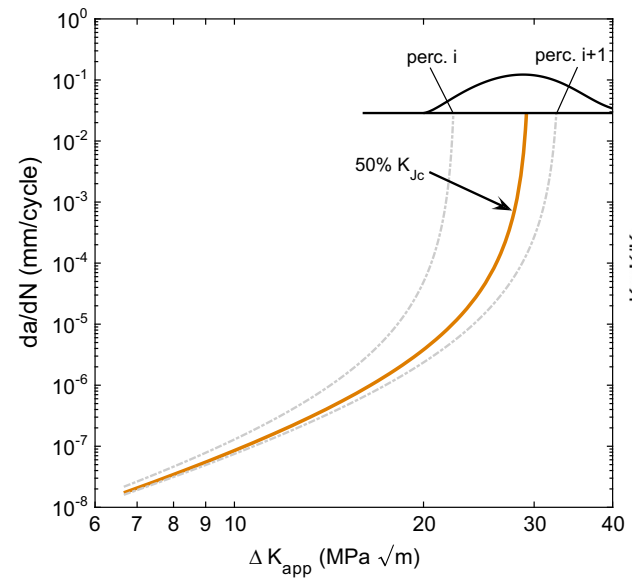

(a)

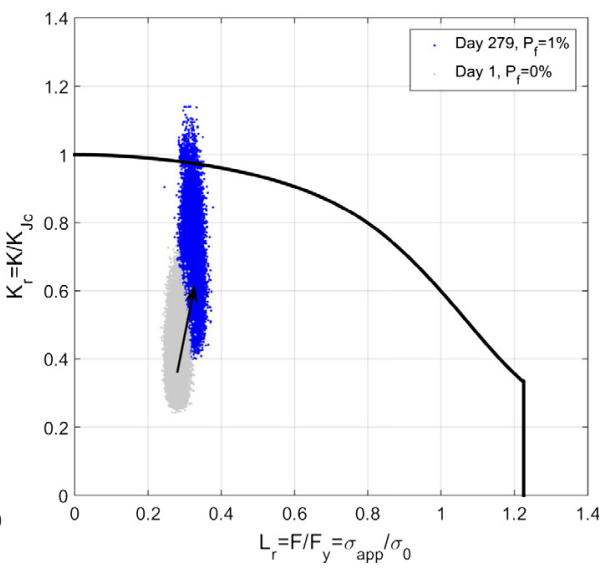

(b)

Fig. 14. Complete probabilistic analysis: (a) different fatigue crack propagation curves for different welds; (b) movement of the point cloud in the FAD from day 1 to day 279 (see Fig. 16 for the whole propagation).

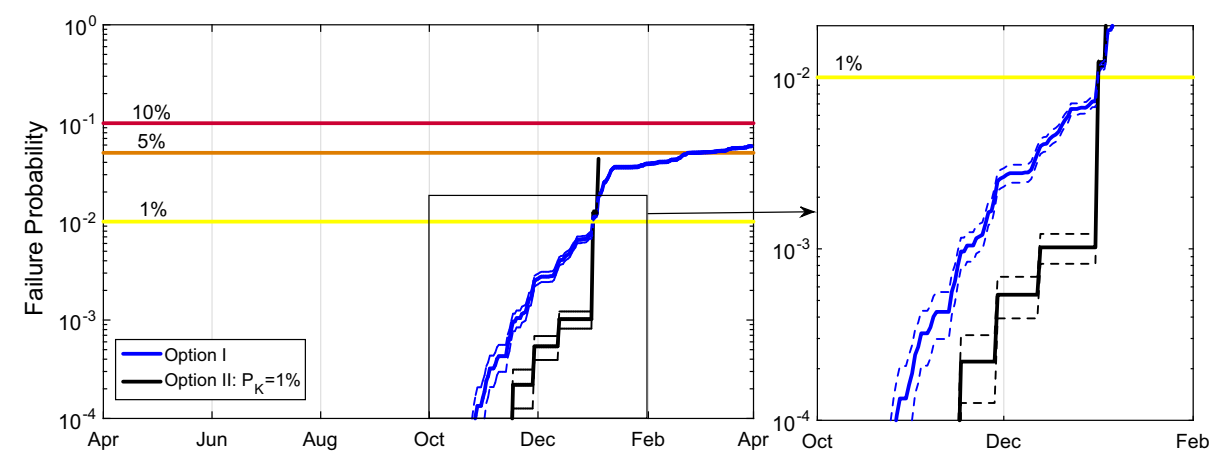

Fig. 15. Comparison between failure probabilities calculated with different methods: complete analysis and fixed- $K_{J c}$-percentile analysis. The $95 \%$ confidence band is reported in dashed lines.
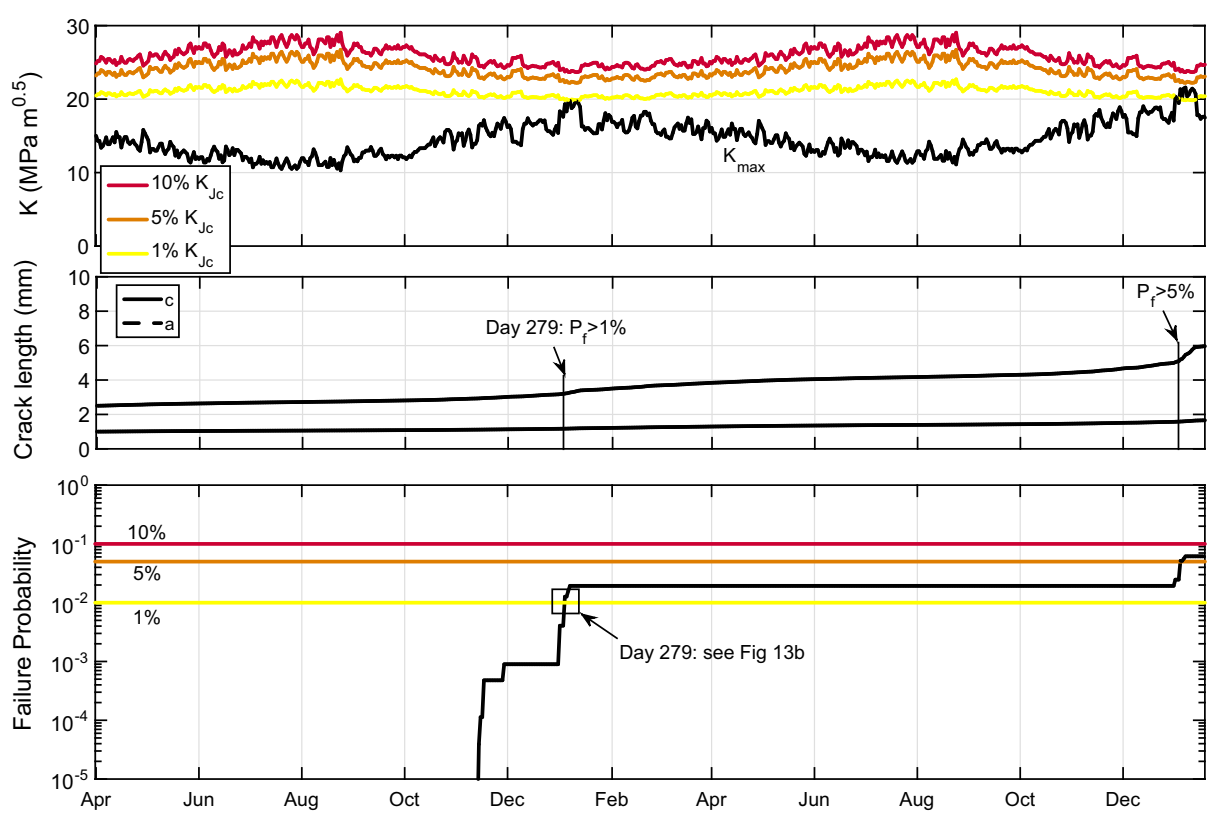

Fig. 16. Propagation and failure probability of a $0.9 \mathrm{~mm} \times 2.225 \mathrm{~mm}$ crack from April 1st. The NDT must be able to detect a crack area of $3.142 \mathrm{~mm}^{2}$. 
year, i.e., prospectively considering NDT inspections in April, August and December. In Fig. 17 it can be seen that, for the same crack starting in August or December, the failure probability is nearly the same and the fracture is expected for the same winter. Since the defect which started in August in December has grown to a bigger size, its failure probability is slightly higher than that of the other one. As a general rule, it can be stated that crack propagation during summertime is of little effect on the expected lifetime of the joint. There are, however, some cases in which a crack reaches a dimension that leads to instability in the previous season, as can be seen for the example of crack propagation from April.

For this reason, the choice of the date of last inspection will influence the results of the model. In order to obtain a reliable life estimation, this variability can be in part compensated by averaging the results of multiple analysis, equally spaced all year.

\subsection{Effect of the environmental temperature}

Another important consideration is that, despite the fact that the main parameter which determines fracture is the outside temperature, this kind of failure is frequent as well in warmer countries, such as South Africa and Australia. This is because, even if minimum temperature is generally higher, this is also true with respect to the maximum temperature and to the neutral one. What counts is the difference $\Delta T$, which is nearly the same in north and south, and so is the thermal stress acting on the crack. The different temperatures influence the material properties too, but since the toughness is in the lower shelf region, the absolute value of the temperature should have a minor influence.

In order to confirm this idea, a simulation was run considering different prospective locations for our reference welded joint. For comparison, the city of Melbourne was chosen, because it has nearly the same $\Delta T$ as Saronno, although its temperature range is shifted to higher values. Temperatures are reported in Table 1: $T_{N}$ for Melbourne was taken as the maximum annual temperature.

Results are shown in Fig. 18: as expected, the same defect with same loading conditions in Saronno and Melbourne reaches instability in the same winter.

\subsection{Railway classification method}

It is common practice to describe the overall loading of a rail track by tonnage weight per day, as suggested, for example, by the standard UIC 714 R [39]. Let as assume two traffic characteristics, one consisting in many light-weight trains and the other in a few heavy convoys, but such that the daily tonnages are identical.
Table 1

Temperature in different cities, year 2014, according to [38].

\begin{tabular}{lllll}
\hline City & $T_{N}$ & $\Delta T_{\max }\left({ }^{\circ} \mathrm{C}\right)$ & $T_{\min }\left({ }^{\circ} \mathrm{C}\right)$ & $T_{\max }\left({ }^{\circ} \mathrm{C}\right)$ \\
\hline Saronno & 33 & 42 & $-9: 20$ & $2: 33$ \\
Melbourne & 41 & 43 & $-1: 27$ & $10: 42$ \\
\hline
\end{tabular}

Following the assessment philosophy outlined in Section 3.3, there will probably be an important difference of both options on the fatigue crack propagation and on the maximum SIF, $K_{\max }$. In the loading cycle, which controls the fracture probability, a difference is to be expected in that the time to failure is smaller for the sequence of heavy trains compared to the lightweight trains. Of cause, it will become much smaller or even disappear for mixed traffic.

To quantify the difference is one aim of the present study. Fig. 19 demonstrates that this is really the case, comparing the damage induced by 50 TAF and 179 CSA (see Section 2.2.1 and Table 2), for an overall daily tonnage of $90.6 \mathrm{t}$. The difference is visible in the maximum SIF, in the crack propagation and, most pronounced, in the $P_{f}$, determined using the simplified method of Section 4.2. This can be an important issue, in particular considering the actual trend of increasing train weight and frequency.

\section{Sensitivity analysis}

In order to verify the sensitivity of the model to two important assumptions ( $\Delta K_{t h} \rightarrow 0$, residual stress profile) a series of simulations were run. In detail, the estimated residual lifetime was calculated considering a traffic composed either by heavy trains (TAF) or by a higher number light ones (CSA), so that the fictitious traffic in terms of tonnage is the same. Crack propagation was assumed to start at three different days of the year (first of April, August and December) and the three lifetimes determined are then averaged.

As for the influence of $\Delta K_{t h}$ on residual lifetime of a welded joint with an initial crack $a_{0}=0.9 \mathrm{~mm}\left(a_{0} / c_{0}=0.4\right)$, the simulations were run considering $\Delta K_{t h}=0$ and the standard threshold for welded materials ([15]).

Comparing the results in terms of residual lifetime, Table 3 shows that using the threshold from BS7910 the life is longer by almost $10 \%$, which means that the parameter does not have an important effect on the residual lifetime.

Note that considering some larger threshold reported in literature (nearly $4.6 \mathrm{MPa} \mathrm{m}^{0.5}$ [13] for $R=0.5$ ) the life prediction would be increased by less than $30 \%$, so the choice of not considering the

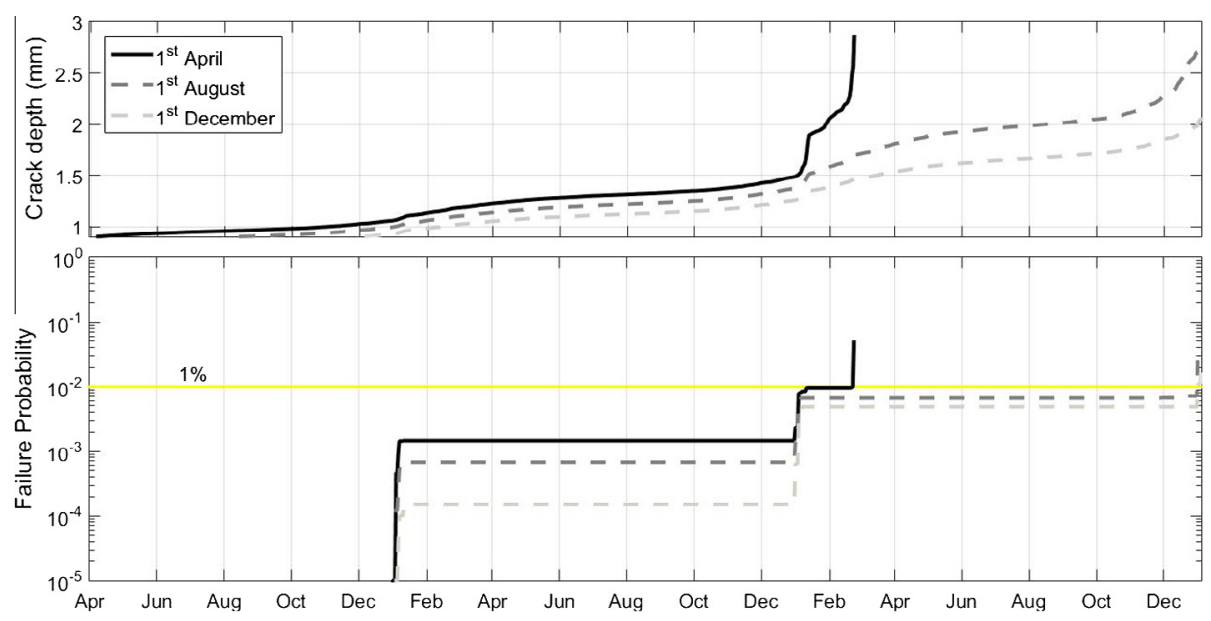

Fig. 17. Comparison between crack depth and $P_{f}$ for the same initial crack size but after inspection at different times in the year. 


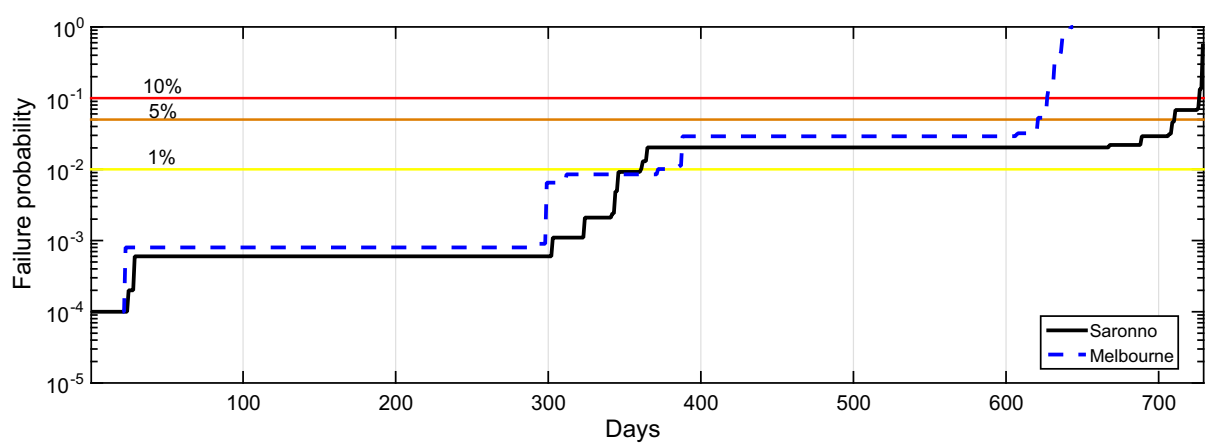

Fig. 18. $P_{f}$ of a $0.9 \mathrm{~mm}$ depth crack growing in Saronno from 1 st January and Melbourne from 1 st July (initial $\left.a_{0} / c_{0}=0.4\right)$

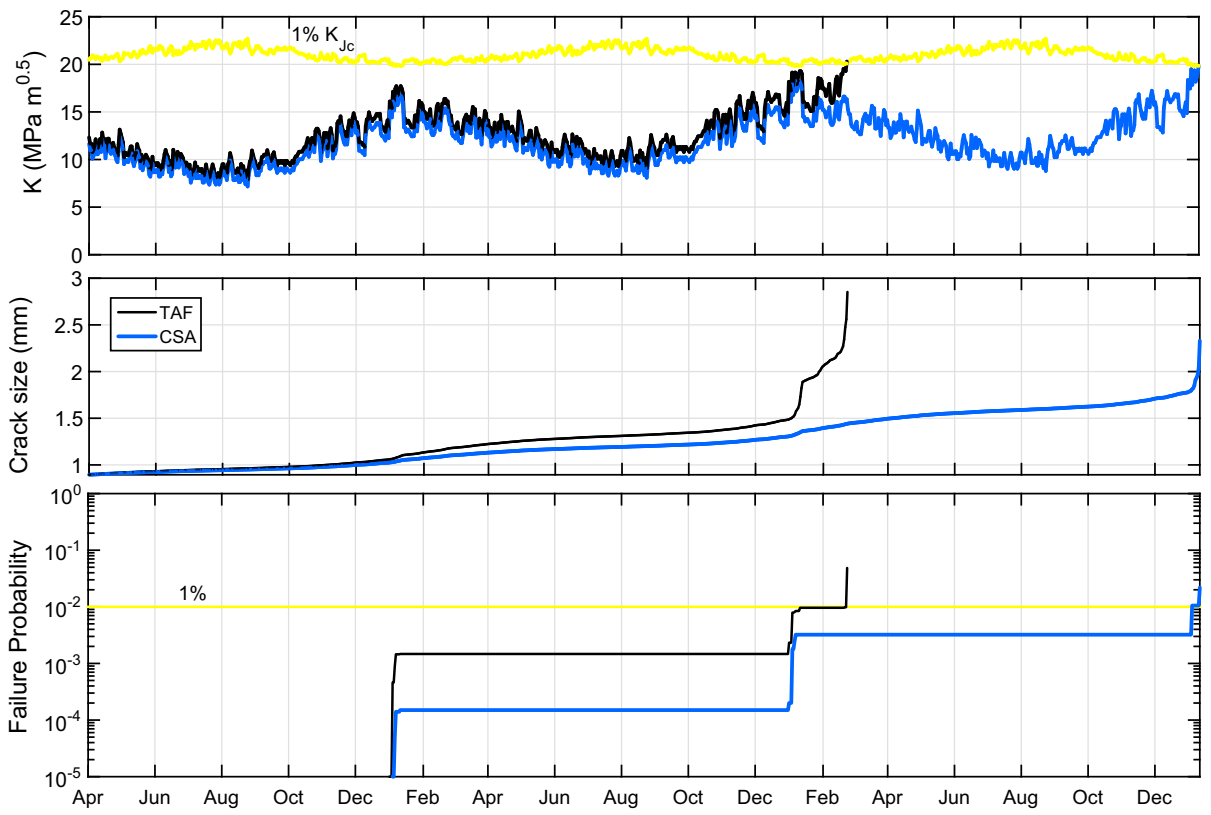

Fig. 19. Crack growth and failure probability determination for TAF and CSA trains having the same daily tonnage.

Table 2

Type and number of trains considered, having the same overall daily tonnage.

\begin{tabular}{llcl}
\hline Train type & Train mass $(\mathrm{t})$ & Trains per day & Line daily tonnage $(\mathrm{t})$ \\
\hline TAF & 1.81 & 50 & 90.6 \\
CSA & 0.51 & 179 & 90.6 \\
\hline
\end{tabular}

crack propagation threshold results in a safe but acceptable hypothesys. However, whether a deeper knowledge of $\Delta K_{\text {th }}$ is achieved, its implementation in the NASGRO curve would be trivial.

The second focus was centered on residual stresses due to the welding process: simulations were run both considering residual stresses or ignoring them. They generally have a huge influence on crack propagation, in particular for cracks in the head and

Table 3

Sensitivity of residual stresses and crack propagation threshold on normalized joint life, calculated simulating the passage of $50 \mathrm{TAF}$ or 179 CSA trains per day $\left(a_{0}=0.9 \mathrm{~mm}\right.$ and temperatures as in Fig. $\left.3 \mathrm{~b}\right)$.

\begin{tabular}{lllll}
\hline & $\sigma_{\text {res }}$ & No $\sigma_{\text {res }}$ & No $\Delta K_{\text {th }}$ & $\Delta K_{\text {th,BS }}$ \\
\hline 50 TAF & 1 & 1.01 & 1 & 1.12 \\
179 CSA & 1.44 & 1.45 & 1.44 & 1.59
\end{tabular}

web region $([21,40])$. However, since at the bottom surface they are limited to really small values, the difference in life prediction of less than $1 \%$. In view of this fact, variations related to the scatter of residual stresses are expected to have a minor influence on the residual lifetime.

\section{Summary and outlook}

A semi-probabilistic model for determining the day by day failure probability of an aluminothermic welded rail joint has been proposed, which is able to take into account the large scatter of the mechanical weld material properties, in particular the fracture toughness. In addition, the effect of ligament plasticity, which is in general neglected, was shown to be important in this kind of analysis.

Fatigue crack propagation was simulated considering a semielliptical crack on the rail foot base at the transition between the rail and the overhanging weld. The analysis shows that the rail temperature is a main factor, which controls failure. In fact, almost any failure happens in wintertime without any difference if the date of the last inspection was in spring or in autumn.

The presented failure mode is a problem of almost all countries, since the essential loading parameter is controlled by the difference between the maximum and the neutral temperature rather 
than by the absolute values of the upper stress intensity factor. Eventually, the common practice to describe the overall loading of a rail track by tonnage weight per day was challenged in that a small number of heavy trains was shown to cause a higher failure probability than a larger number of light trains. This is because the crack propagation is faster in the first case and the maximum SIF and ligament plasticity correction are higher.

The aim of the present paper was the development of a simple probabilistic model with a minimum computational time. A sensitivity analysis has supported the simplifications introduced. Nevertheless, the model could be further improved by using more realistic input information, such as dynamic loading train spectra, precise residual stresses distributions.

\section{Acknowledgments}

Experiments were carried out in the framework of a research contract between Politecnico di Milano, Dept. Mechanical Engineering and FNM. With respect to the development of the probabilistic method, S. Romano acknowledges the period he spent at BAM Federal Institute for Materials Research and Testing, Division 9.1, Berlin.

\section{References}

[1] M.J.M.M. Steenbergen, R.W. Van Bezooijen, Wheel-Rail Interface Handbook, Elsevier, 2009, ISBN 9781845694128, http://dx.doi.org/10.1533/ 9781845696788.1.377.

[2] U. Zerbst, M. Schödel, R. Heyder, Damage tolerance investigations on rails, Eng. Fract. Mech. 76 (17) (2009) 2637-2653, http://dx.doi.org/10.1016/j. engfracmech.2008.04.001.

[3] U. Zerbst, R. Lundén, K.O. Edel, R. Smith, Introduction to the damage tolerance behaviour of railway rails - a review, Eng. Fract. Mech. 76 (17) (2009) 25632601, http://dx.doi.org/10.1016/j.engfracmech.2009.09.003.

[4] D. Manenti, Analisi di propagazione fratture in giunti alluminotermici Ms, Politecnico di Milano, Milan, Italy, 2013.

[5] U. Zerbst, R. Ainsworth, H. Beier, H. Pisarski, Z. Zhang, K. Nikbin, et al., Review on fracture and crack propagation in weldments - a fracture mechanics perspective, Eng. Fract. Mech. 132 (2014) 200-276, http://dx.doi.org/10.1016/j. engfracmech.2014.05.012.

[6] K. Wallin, Probabilistisk säkerhetsvärdering PROPSE - Material-parametrar, 1998.

[7] ASTM E1820, Standard Test Method for Measurement of Fracture Toughness 1, ASTM (2013) 1-54, http://dx.doi.org/10.1520/E1820-11.

[8] ASTM E1921, Standard Test Method for Determination of Reference Temperature, To, for Ferritic Steels in the Transition Range, Am. Soc. Test. Mater. (2013) 1-26.

[9] W. Nelson, J. McCool, W. Meeker, Applied life data analysis, Wiley Series in Probability and Statistics, vol. 1, Wiley Online Library, 1982, ISBN 0471094587, http://dx.doi.org/10.1002/qre.4680010114.

[10] A. Mohassel, A. Kokabi, P. Davami, Mechanical and metallurgical properties of wide-gap aluminothermic rail welds, Iran. J. Mater. Sci. Eng. 8 (4) (2011) 27 33.

[11] P. Mutton, E. Alvarez, Failure modes in aluminothermic rail welds under high axle load conditions, Eng. Fail. Anal. 11 (2) (2004) 151-166, http://dx.doi.org/ 10.1016/j.engfailanal.2003.05.003.

[12] P. Mutton, R. Moller, M. Steinhorst, Improving the performance of aluminothermic rail welding technology, through selective alloying of the rail head, in: Int. Heavy Haul Railw. Conf. Canberra, 2001, pp. 331-338.

[13] G. Demofonti, Comisión Europea, Role of Residual Stresses and Microstructure on Fatigue Initiation and Crack Growth in Welded Rails, Office for Official Publications of the European Communities, 2001, ISBN 9789289415897.

[14] J.C.J. Newman, A crack opening stress equation for fatigue crack growth, Int. J. Fract. 24 (4) (1984).
[15] British Standard, Guide to Methods for Assessing the Acceptability of Flaws in Metallic Structures Tech. Rep., 2005.

[16] ASTM E647, Standard Test Method for Measurement of Fatigue Crack Growth Rates (2013), http://dx.doi.org/10.1520/E0647-13A.2.

[17] U. Zerbst, M. Vormwald, R. Pippan, H.-P. Gänser, C. Sarrazin-Baudoux, M. Madia, About the fatigue crack propagation threshold of metals as a design criterion - a review, Eng. Fract. Mech. (2016) 190-243.

[18] G. Hunt, Review of the effect of track stiffness on track performance Tech. Rep., 2005.

[19] E. Berggren, Railway Track Stiffness - Dynamic Measurements and Evaluation for Efficient Maintenance. (2009). ISBN 9789174152937.

[20] Rete Ferroviaria Italiana, Norme tecniche per la saldatura in opera di rotaie, eseguita con i procedimenti alluminotermico ed elettrico a scintillio, 2001.

[21] A. Skyttebol, B. Josefson, J. Ringsberg, Fatigue crack growth in a welded rail under the influence of residual stresses, Eng. Fract. Mech. 72 (2) (2005) 271285, http://dx.doi.org/10.1016/j.engfracmech.2004.04.009.

[22] J.C.J. Newman, I. Raju, Stress-intensity factor equations for cracks in threedimensional finite bodies subjected to tension and bending loads, in: S. Atluri (Ed.), Comput. Methods Mech. Fract, Elsevier Science Publishers, 1986, pp. 311-334. chap. 9.

[23] X. Wang, S. Lambert, Stress intensity factors and weight functions for high ratio semi-elliptical surface cracks in finite-thickness plates, Eng. Fract. Mech. 57 (I) (1997) 13-24.

[24] S. Courtin, C. Gardin, G. Bézine, H.B.H. Hamouda, Advantages of the j-integral approach for calculating stress intensity factors when using the commercial finite element software \{ABAQUS\}, Eng. Fract. Mech. 72 (14) (2005) 21742185, http://dx.doi.org/10.1016/j.engfracmech.2005.02.003.

[25] I. Salehi, Fatigue and Fracture Behaviour of Aluminothermic Rail Welds under High Axle Load Conditions [Ph.D. thesis], Swinburne University of Technology, 2012.

[26] X. Wang, S. Lambert, Local weight functions for semi-elliptical surface cracks in finite thickness plates, Theoret. Appl. Fract. Mech. 23 (3) (1995) 199-208.

[27] Ferrovienord, Istruzione Operativa: Controllo Manuale con Ultrasuoni PhasedArray, 2102

[28] W. Richard, Hertzberg: Deformation and fracture mechanics of engineering materials, fourth ed., 1996. http://dx.doi.org/10.1016/0261-3069(84)90070-0.

[29] British Energy Generation Ltd (BEGL) - now Électricité de France (EDF), R6, Revision 4: Assessment of the Integrity of Structures Containing Defects, Barnwood, Gloucester, 2004.

[30] U. Zerbst, M. Schödel, S. Webster, R. Ainsworth, Fitness-for-Service Fracture Assessment of Structures, Academic Press, 2007, ISBN 9780080449470.

[31] U. Zerbst, R. Ainsworth, M. Madia, Reference load versus limit load in engineering flaw assessment: a proposal for a hybrid analysis option, Eng. Fract. Mech. $91 \quad$ (2012) 62-72, http://dx.doi.org/10.1016/j. engfracmech.2011.10.018.

[32] U. Zerbst, S. Beretta, G. Köhler, A. Lawton, M. Vormwald, H. Beier, et al., Safe life and damage tolerance aspects of railway axles - a review, Eng. Fract. Mech. 98 (2013) 214-271, http://dx.doi.org/10.1016/j.engfracmech.2012.09.029.

[33] S.L. Grassie, Measurement of railhead longitudinal profiles: a comparison of different techniques, Wear 191 (1) (1996) 245-251.

[34] M. Bocciolone, A. Caprioli, A. Cigada, A. Collina, A measurement system for quick rail inspection and effective track maintenance strategy, Mech. Syst. Signal Process. 21 (3) (2007) 1242-1254.

[35] C. Annis, Probabilistic life prediction is'nt as easy as it looks, in: W.S. Johnson, B. Hilberry (Eds.), Probabilistic Aspects of Life Prediction, ASTM STP 1450, American Society for Testing And Materials, West Conshohocken (PA), 2004.

[36] Damage Tolerance Assessment Handbook, Federal Aviation Administration, 1993.

[37] A. Haldar, S. Mahadevan, Probability, Reliability, and Statistical Methods in Engineering Design New York, 2000.

[38] Weather Underground, 2015. <www.wunderground.com>.

[39] UIC 714R, Classification des voies des lignes au point de vue de la maintenance de la voie, Tech. Rep., 2009.

[40] H. Desimone, S. Beretta, Mechanisms of mixed mode fatigue crack propagation at rail butt-welds, Int. J. Fatigue 28 (2006) 635-642, http://dx.doi.org/10.1016 j.ijfatigue.2005.07.044.

[41] M. Cannavò, D. Cocciaglia, A. Raimondi, Sulle rotture di rotaie, deviatoi e giunzioni nel 1998, 1999.

[42] F. Lawrence, Y.R. Chen, J. Cyre, C. Barkan, Strategies for Improving the Fatigue Resistance of Thermite Weldments, 2001. 